\title{
A artesania de um fazer a prática do trabalho de educadores
}

DINORA TEREZA ZUCCHETTI

Universidade Feevale, Novo Hamburgo, RS, Brasil

ELIANA PEREZ GONÇALVES DE MOURA

Universidade Feevale, Novo Hamburgo, RS, Brasil

MAGALI MENDES DE MENEZES

Universidade Federal do Rio Grande do Sul, Porto Alegre, RS, Brasil

RESUMO

O artigo apresenta resultados de pesquisa em práticas de educação não escolar. Inicialmente delineia uma breve revisão sobre práticas socioeducativas, enquanto conceito e intervenção. Por meio de entrevistas individuais e da formação de grupos de discussão com educadores atuantes em projetos socioeducativos, buscou-se uma reflexão sobre suas práticas, levando em consideração as seguintes categorias de análise: formação, trabalho e sua natureza, conceito de socioeducativo, estratégias pedagógicas. A pesquisa então demonstra alguns resultados preliminares da investigação "Práticas de educação não escolar de sujeitos que atuam em projetos socioeducativos", entre eles, um traçado do perfil do educador e as principais categorias que advêm das análises das entrevistas. A análise, mesmo que parcial, evidencia quem são esses sujeitos e como eles se produzem, além de oportunizar um conjunto de reflexões sobre práticas de educação que são contextualizadas numa dada realidade e produtoras de novas sensibilidades.

PALAVRAS-CHAVE

práticas socioeducativas; formação; educadores. 


\section{THE CRAFT OF DOING: PRACTICES OF EDUCATORS}

\section{ABSTRACT}

The paper presents the results of research into practices in non-school education. It initially outlines a brief review about social-educational practice as a concept and an intervention. Based on individual interviews and discussion groups with educators in social and educational projects, we reflected on their practices considering the following categories of analysis: training, work and its nature, concept of social-education, pedagogical strategies. The research shows some preliminary results in "Practices of non-school education with people that work on social-educational projects", among them, the educator's profile and the main categories that arise from the interview analysis. It partially, shows who these people are and how they provide opportunities to reflect on education practices that are contextualized in a reality and new sensibilities.

\section{KEYWORDS}

socio-educational practices; education; educators.

\section{LA ARTESANÍA DE UN HACER: LA PRÁCTICA DEL TRABAJO DE EDUCADORES}

\section{RESUMEN}

El artículo presenta resultados de investigación de prácticas de educación no escolar. Inicialmente, delinea una breve revisión sobre prácticas socioeducativas, en relación a concepto e intervención. Mediante entrevistas individuales y la formación de grupos de discusión con los educadores que trabajan en proyectos socioeducativos, se buscó una reflexión sobre sus prácticas considerando las siguientes categorías de análisis: formación, trabajo y su naturaleza, concepto de socioeducativo, estrategias pedagógicas. El trabajo revela algunos resultados previos a la investigación "Práticas de educação não escolar de sujeitos que atuam em projetos socioeducativos", entre los cuales, un rasgo del perfil del educador y las principales categorías que advienen de los análisis de las entrevistas. Dichos análisis, aunque parciales, evidencian quiénes son estos sujetos y cómo ellos se forman, ademásde originar un conjunto de reflexiones sobre prácticas de educación, que son contextualizadas en una determinada realidad y productoras de nuevas sensibilidades.

PALABRAS CLAVE

prácticas socioeducativas; formación; educadores. 
Não há palavra verdadeira que não seja práxis. Daí que dizer a palavra verdadeira seja transformar o mundo.

Freire, 1981.p. 91

\section{INTRODUÇÃO}

As indagações que vamos construindo ao longo deste texto emergem de um cenário em que os projetos socioeducativos, foco central desta análise, desafiam-nos a repensar novos sentidos para a educação. Nesse sentido, cabe indagar o que significa dizer a "palavra verdadeira", anunciada por Freire na epígrafe acima? A palavra aqui assume a força daqueles que se pronunciam, que ao falar se produzem e produzem significados para suas práticas.

É sobre esses diferentes significados que traçamos algumas análises por meio da fala de educadores, em uma investigação financiada pelo Conselho Nacional de Desenvolvimento Científico e Tecnológico (CNPq), iniciada em 2010, e que objetiva conhecer a ação metodológica e as finalidades de práticas de educação no campo social, delimitando-as a programas e/ou projetos socioeducativos. O objetivo da pesquisa é indagar sobre como o fazer de educadores impacta a vida dos jovens e quais são as possíveis "novas versões" de projetos socioeducativos demonstradas pela experiência, perguntando como se formam esses trabalhadores e que questões advêm da sua formação. Para tanto, a investigação, de tipo qualitativa, na modalidade de uma pesquisa-formação, é constituída por um grupo de 11 educadores que preenchem o requisito de estar atuando em projetos socioeducativos executados por organizações governamentais, não governamentais e do terceiro setor na região metropolitana de Porto Alegre/RS.

Tais projetos, de caráter compensatório, ao surgirem no Brasil, nos primórdios dos anos 1970, ainda não evidenciavam um campo de dissensos entre duas grandes áreas do conhecimento envolvidas nessas práticas: a educação e a assistência social. Naquela época, ainda capitaneados por práticas clientelistas, ações assistenciais/ assistencialistas serviam para a manutenção da condição de pobreza de parcelas da população brasileira, ao mesmo tempo em que conformavam um quadro que referendava a supressão de uma ideia de infância por meio do trabalho infantojuvenil, do confinamento institucional dos abandonados e do consequente enfraquecimento de laços de afinidade entre crianças e jovens, vulnerabilizados socialmente, com suas famílias e comunidades.

A partir da década de 1990, com o advento do Estatuto da Criança e do Adolescente (ECA), os projetos socioeducativos sofreram transformações significativas, enquanto concepção e intervenção. Passaram a firmar-se mais por outro tipo de efetividade social, agora relacionada à emergência de políticas públicas de atenção à infância e à juventude, fato que provocou o surgimento de uma tensão entre a dimensão assistencial e a crescente dimensão educativa de tais projetos. É essa realidade que temos presenciado ao longo das duas últimas décadas, por meio do acompanhamento sistemático de experiências no âmbito da extensão, da pesquisa e do ensino e a partir de onde vemos ações socioeducativas deslizarem do trabalho 
infantil para a produção do sujeito trabalhador, do controle do ócio para práticas de socialização pautadas na ocupação do tempo livre e, mais recentemente, da cultura do trabalho ao trabalho da cultura.

Neste artigo, além de revisitar o que tem sido definido como conceito e intervenção de práticas socioeducativas, apresentamos uma versão dos resultados parciais da pesquisa. Nela, destacamos o perfil dos educadores pesquisados, bem como a emergência dos conceitos de formação e atividade, advindos de suas práticas, que são analisadas nas entrevistas individuais.

\section{OS SOCIOEDUCATIVOS E SEUS DIFERENTES SIGNIFICADOS HISTÓRICOS}

Segundo Carvalho e Azevedo (2004, p. 1), os projetos socioeducativos agregam atividades complementares à escola e conjugam educação e proteção social, firmando-se como "ações que fazem da educação para o convívio em sociedade e para o exercício da cidadania uma estratégia de proteção à infância e à juventude”. São experiências que, segundo Zucchetti e Moura (2010), habitam um campo teórico denominado de "educação não escolar", o qual tem sido definido por Haddad (2009, p. 370) como constituído por práticas "desenvolvidas fora do contexto da escola e [que] estão voltadas principalmente para a formação política e cidadã e no atendimento das necessidades de natureza econômica, socioambiental e cultural".

Das concepções pelas quais partem os autores citados, é possível afirmar que os socioeducativos são práticas de educação não escolar cujas ações de promoção da cidadania e de proteção social, voltadas às crianças e jovens socialmente vulnerabilizados, evidenciam a base compensatória de tais programas/projetos. A constatação de que determinados sujeitos sociais demandam por espaços de proteção extrafamiliar remete, indubitavelmente, a uma análise crítica da realidade social.

Muito embora os indicadores oficiais apontem para a diminuição nos níveis de pobreza no Brasil, no sentido de uma "generalizada melhora social" (Brasil,2010, p. 3), é sabido que a situação socioeconômica de setores populares, por fora das estatísticas, não cessa de gerar excluídos de toda ordem. Referimo-nos à crise da sociedade salarial, fato que desde há muito vem assolando milhões de brasileiros, crise esta que se tem tornado ainda mais perversa nos últimos anos em virtude da concentração da renda entre os mais ricos. Além disso, o incremento populacional nas grandes cidades e suas consequências sobre o viver, a precarização das relações de trabalho, os crescentes índices de violência, entre outros, precisam ser evidenciados como indícios do processo de exclusão social presente na sociedade brasileira.

Dessa forma, partindo do pressuposto de que toda situação de pobreza socioeconômica é excludente, entendemos que a existência de projetos socioeducativos e a presença de crianças e jovens neles assistidos demonstram que programas e projetos dessa natureza gerenciam a desigualdade e a exclusão social. Outrossim, as políticas compensatórias, ao serem oferecidas como condição de acesso a estágios iniciais de cidadania, servem também como um modo de neutralizar e padronizar as formas do humano. É inegável que essas políticas também têm servido para inserir 
socialmente grandes contingentes de jovens e os próprios educadores (em geral, também jovens) em algum patamar da cidadania. ${ }^{1}$ No entanto, essa compreensão não é suficiente para analisar as engrenagens sutis em que se encontram enredadas as práticas sociais, que refletem uma diversidade cultural, e as formas de expressão social da infância e da juventude.

Vale destacar que os projetos socioeducativos, por nós referidos, cada vez mais têm sido propostos não mais exclusivamente pelo setor público governamental, assim como ocorria quando este oferecia programas e projetos ainda inspirados na doutrina da situação irregular. Ainda que nesse período já existissem organizações governamentais e não governamentais ocupadas em intervir, por meio de ações socioeducativas, no sentido de transformar o sujeito de falta em sujeito de direito prerrogativa fundamental para o movimento pró-ECA -, é inquestionável que o aumento quantitativo de programas/projetos socioassistenciais se deu a partir da década de 1980. Nesse período ocorreu o enxugamento da máquina do Estado e a emergência do chamado terceiro setor, que, aos poucos, tornou-se um forte demandatário e executor de práticas socioeducativas, que passaram a ser apresentadas às populações mais vulnerabilizadas como uma alternativa de inclusão social.

Evidentemente, entre os inúmeros fatores que estão na base da emergência e crescimento do terceiro setor, no mundo todo, destaca-se a chamada terceira revolução industrial, cujos avanços tecnológicos produziram uma importante reformulação do processo produtivo, provocando um fabuloso aumento nos índices de produtividade e a consequente eliminação de milhões de postos de trabalho.

Ao analisar as transformações ocorridas no "mundo do trabalho", Antunes (2003) apontou a crise do Estado de bem-estar social como um dos fenômenos que justificou a crescente expansão do trabalho no terceiro setor. Especialmente, a partir dos anos 1980, o Estado brasileiro tornou-se incapaz de sustentar sua ação social, como provedor de certos tipos de bens, estimulando a sociedade a organizar-se para garantir a provisão desses bens. De fato, a ausência do Estado provocou o redirecionamento de recursos públicos ao terceiro setor, trazendo como resultado a absorção de milhares de pessoas nas chamadas empresas de caráter assistencial, sem fins lucrativos, que passaram a surgir nessa época como empreendimentos que se colocaram como a "terceira via", posto que se situaram fora do âmbito estatal e à margem do mercado.

Conforme Antunes (idem, p. 57), ante um cenário de profundas transformações o terceiro setor emergiu "assumindo uma forma alternativa de ocupação,

1 As políticas sociais no Brasil - em especial aquelas gestadas nas últimas décadas e, de forma mais eficaz, a partir do Governo Lula -, ao considerarem a complexidade da realidade social como altamente vulnerabilizadora, oportunizam que programas como o Bolsa Família e o Projovem Adolescente, do Ministério de Desenvolvimento Social (MDS), por exemplo, apresentem-se como ações de proteção integrada (e integradora) e de inserção de jovens em ações ditas inclusivas. Nessa mesma perspectiva, o Programa Mais Educação, do Ministério da Educação (MEC), também objetiva pela prática socioeducativa realizar ações de proteção e inclusão social, ao ampliar o espaço/tempo da escola para determinadas crianças e jovens. 
através de empresas de perfil mais comunitário, motivadas predominantemente por formas de trabalho voluntário, abarcando um amplo leque de atividades". Como desdobramento direto da retração do mercado de trabalho formal, em um quadro de "desemprego estrutural", a expansão do terceiro setor, tornou-se alvo de interesse de estudos, a partir da década de 1990, na medida em que ele passou a ser visto como uma alternativa viável de articulação entre o público e o privado. De acordo com Calegare e Júnior (2009, p. 131),

São inúmeros os trabalhos justificando a emergência do terceiro setor, o panorama que o sustenta - sempre muito otimista - e os modos como montar e gerir uma organização sem fins lucrativos, todos permeados pela "promessa" de transformação social. O contraponto crítico só é possível quando abordado segundo paradigmas além da gestão, como ciências humanas e sociais, tais quais: Economia, Sociologia, Ciência Política e Psicologia Social e Política. A partir delas é possível compreender como o Terceiro Setor está imerso numa gama de contextos que não aparecem ao olhar desatento.

Nesse sentido, Antunes (2003) afirma ser um equívoco considerar o terceiro setor como uma alternativa real e duradoura às mutações do trabalho, posto que esse segmento jamais será capaz de substituir a sociedade capitalista e de mercado. Sua função é apenas manter precariamente ocupados os milhões de trabalhadores que foram expulsos do mercado formal por conta da extinção de inúmeros postos de trabalho.

De acordo com Antunes (idem, p. 57), reintegrar os trabalhadores pode ser considerado um traço positivo do terceiro setor, posto que "estes seres sociais veem-se não mais como desempregados, plenamente excluídos, mas como pessoas capazes de realizar atividades efetivas, dotadas de algum sentido social e utilidade". Contudo, trata-se de uma pseudoincorporação, na medida em que o terceiro setor emergiu e consolidou-se como um campo de precarização e flexibilização dos direitos sociais.

\section{O EDUCADOR DA CIDADE DE NOVO HAMBURGO: UMA APROXIMAÇÃO}

Os projetos socioeducativos, de forma crescente, vêm sendo implementados por entidades do terceiro setor, "prestando serviços" de educação e acolhimento de crianças e jovens em situação de "vulnerabilidade" e, também, absorvendo a mão de obra de uma significativa parcela da população de jovens em busca de inserção no mercado de trabalho.

Assim, nesse campo de "prestação de serviço", acolhendo crianças e jovens, cresce o número de atividades realizadas por profissionais de diversas áreas do conhecimento, os quais, no âmbito desses espaços, geralmente são nomeados de "educadores sociais". ${ }^{2} \mathrm{Na}$ sequência, apresentam-se o perfil desses sujeitos bem

2 Do ponto de vista formal, a ocupação educador social foi recentemente inscrita no Cadastro Brasileiro de Ocupação (Associação, 2010). Sob o n. 5.153/05, a ocupação 
como algumas das temáticas que emergiram das entrevistas individuais, realizadas no período de abril a junho de 2011. Essas entrevistas compuseram a primeira fase do delineamento metodológico da pesquisa-formação e, a partir da sistematização realizada e da análise, considerando-se a recursividade de determinadas expressões e ideias, ${ }^{3}$ emergiram as seguintes categorias temáticas: formação, trabalho, conceitos, dimensões e planejamento nos socioeducativos.

\section{O PERFIL DOS EDUCADORES}

Dos 11 educadores que participaram da pesquisa na modalidade entrevista individual, 4 atuam em organizações governamentais e 7 estão vinculados aos espaços não governamentais e ao terceiro setor. Quanto ao sexo, 7 são homens e 4 são mulheres. Com referência à formação acadêmica, os educadores são de áreas diversas: 5 possuem formação em pedagogia e 2 em educação física. As áreas de teologia, letras, história e psicologia estão representadas por um educador por área. Quanto à situação acadêmica, 8 são graduados, 1 está cursando o ensino superior e 2 encontravam-se, à época da coleta de dados, na modalidade matrícula suspensa (trancada). Com relação ao tempo de atuação profissional em projetos socioeducativos, a configuração apresentada é: 6 atuaram em período que compreende de 1 a 3 anos, 4 têm de 4 a 6 anos e somente 1 possui mais de 7 anos.

Destaca-se que, levando em conta as funções que exerciam tanto no trabalho anterior quanto no atual, somente 2 dos participantes não atuavam no campo da educação. Os outros 9 trabalhavam como professores de teatro e educação infantil e como educadores, o que demonstra que, na sua maioria, possuem experiência em educação. Quanto ao cargo, é importante observar que, à exceção do diretor, todos exercem a função de educador, porém a forma como estão vinculados formalmente ao trabalho é diversa. Essa diversidade agrega, além da figura do educador, as de padeiro, recreacionistas, estagiários. Em relação ao vínculo de trabalho, observamos que somente 4 têm vínculo regido pela Consolidação das Leis do Trabalho (CLT) e/ou por estatuto próprio, no caso de servidor público. Entre os demais, destacam-se as modalidades: contrato por tempo determinado, pagamento a autônomo, estagiário.

O perfil antes descrito demonstra as características de precarização do trabalho, compatíveis com o chamado terceiro setor, o qual encerra em si a contradição de constituir-se em segmento que apenas possui um papel de funcionalidade ao sistema capitalista, conforme referido anteriormente. Com efeito, o perfil do grupo de educadores, no que tange a sua função e condições de trabalho, parece estar marcado pela precarização e pela flexibilização dos direitos sociais, heranças do enxugamento do Estado e da consequente emergência e consolidação do terceiro setor.

educador social está no mesmo registro de educador de rua, aos quais se atribui a atenção, defesa e proteção a pessoa em situação de risco.

3 As entrevistas foram realizadas após a assinatura do Termo de Consentimento Livre e Esclarecido, aprovado no Comitê de Ética em Pesquisa da Universidade Feevale, sob o registro n. 7.08.01.10.1275. Atualmente, a investigação realiza os encontros do grupo de pesquisa-formação, que até a presente data somam oito encontros. 


\section{AS CATEGORIAS TEMÁTICAS: AS “PALAVRAS VERDADEIRAS” E SUA PRÁXIS}

Das questões postuladas nas entrevistas, e considerando-se os objetivos da pesquisa, surgiram temáticas que foram aglutinadas de acordo com sua emergência e recursividade.

É relevante informar que, com base nas entrevistas individuais - realizadas como uma primeira fase da pesquisa -, foi possível aglutinar inúmeros temas que perpassaram a fala dos educadores; entretanto, somente quando as temáticas foram submetidas aos educadores, nos grupos de discussão - segunda fase da investigação -, é que foi possível identificar de forma mais conclusiva o que passamos a nomear de categorias. São elas: formação, trabalho, conceito, dimensões e planejamento dos socioeducativos, as quais, nesta seção, vêm incorporadas à fala dos próprios educadores.

\section{Definindo a formação e o trabalho enquanto atividade}

Sobre a categoria formação, podemos afirmar que ela é "forjada no trabalho" e que conta de forma inconteste com a presença do outro [educador]. Aprende-se com os colegas de trabalho, afirma o Educador I: "Do que eu conheço, de outros educadores que eu tenho contato, é que a formação é forjada no trabalho, sempre no trabalho". Na sequência, acrescenta: "Me sinto muito amparado pelos meus colegas, sabe?”. Ou, como afirma o Educador J, “A gente vai aprendendo na prática, fui aprendendo com elas [educadoras]. Assim, fazendo, sem muito referencial. Foi bem na prática mesmo". Ou ainda, segundo a Educadora C: "Tu descobre que tu aprende com o outro que tá sentado numa mesa comum, igual [...]. Neste momento tu te posiciona. Dar este passo, eu acho que é aprender".

"Bem, agora é contigo!". Foi assim que a Educadora C disse ter sido inserida no trabalho. "O que é que eu vou fazer? Caí de paraquedas! Bom, aí eu comecei a trabalhar, comecei a observar as outras [educadoras], como é que faziam”, relembra. A dimensão prática da educação, na perspectiva da formação, é um elemento fundamental nos socioeducativos e existe em abundância nessa modalidade de educação, referendam os educadores. A docência na educação infantil e/ou o trabalho anterior como educadores são marcadores da formação e da ação.

Foi assim, eu tinha uma experiência muito grande na área da educação infantil, anos iniciais, então eu parei um tempo depois de dez anos de trabalho [faz referência à necessidade de cuidar dos próprios filhos] então eu fazia Pedagogia para poder entrar na área. (Educadora $\mathrm{C}$ )

Da mesma maneira, entre os educadores, a formação não é deslocada da experiência, seja esta a da maternidade ou a que se origina na realidade da maioria deles, que referem histórias de trabalho infantil, situação familiar de pobreza e o fato de terem, eles próprios, sido acolhidos em socioeducativo. Uma realidade de infância muito parecida com a dos jovens que participam das oficinas de esporte é o que destaca o Educador $\mathrm{K}$. 
A dificuldade financeira de não ter o que comer é muito parecida com a realidade deles; meu chuveiro era uma latinha de azeite com uma mangueira dentro, morava em uma casinha de duas peças. Eu tinha um pai que era alcoólatra e violento, e uma mãe que passava muita dificuldade.

Quando frequentou o socioeducativo, dos 7 aos 14 anos, a Educadora $\mathrm{C}$ já brincava de ser educadora. "Já iniciei brincando disto e depois gostei, fui tomando gosto e fui estudar. Fiz o magistério, depois parti para uma graduação que foi a faculdade de educação física". Por sua vez, o Educador A relembra sua adolescência: "Eu na verdade engraxava sapatos. Eu engraxei dos 13 até os 14 anos [...] daí o pessoal da assistência, eles cuidavam da gente, mas para não dar problemas. Agora é diferente, trabalhamos com oportunidades".

As experiências de trabalho dos educadores inseridos no meio popular parecem remetê-los à vivência da própria biografia. Mesmo que os educadores, pela condição de trabalho e/ou formação, pareçam demonstrar certo afastamento da realidade das classes populares, sua memória assume um retornar, um reviver e uma identificação intensa com a realidade em questão. Se para alguns adentrar o universo da educação no campo social e/ou dos projetos socioeducativos diz de uma prática nova, para outros tantos representa uma (re)imersão na própria experiência vivida na infância. Experiência vivida e trabalho se misturam em um espaço de incessante aprender.

Sobre o que poderíamos chamar de formação em serviço, a Educadora $\mathrm{C}$ destaca: "Eu, agora no Projovem, a gente tem vivido toda sexta-feira momentos de formação, e eu acredito demais que isto faz a diferença". Também se referem à experiência acadêmica ressaltando o papel da universidade na construção do conhecimento formal, mas essa modalidade de formação é reconhecida como complementar às demais, e não necessariamente como o ponto de ancoragem.

Quando indagados sobre a necessidade de cursos específicos no campo da educação não escolar, a exemplo da pedagogia social, os educadores afirmam não ser necessário tal especificidade. $\mathrm{O}$ Educador $\mathrm{J}$ acrescenta que aquilo que se aprende na sala de aula, na universidade não é aplicado de forma linear: "Isto que tá acontecendo aqui a gente já viu lá na faculdade, daí a gente acaba adaptando. Por exemplo, eu não vou usar o que diz, ao pé da letra, o Paulo Freire, mas eu uso muito a forma de pensar".

Sobre a categoria trabalho enquanto atividade profissional (Schwartz, 2006), sobressaem, na fala dos entrevistados, sentimentos de satisfação, doação, missão, cumplicidade para referirem-se à sua implicação com as atividades. A contínua comprovação de implicação com a atividade, no sentido da formação de vínculos, é referendada como algo que propulsiona a ação educativa.

Eu mentiria se dissesse que só atuo profissionalmente. Mexe muito com o pessoal, é uma transformação constante. Eu digo assim, que a minha vida pessoal é outra vida no decorrer dessa caminhada do trabalho social. E não é uma coisa assim: mudei [...] é uma transformação que acontece dia a dia, com cada acontecimento, com cada fala dos educadores, com cada vivência que a gente tem 
com eles. É uma aprendizagem sem fim. [...] Depois que a gente entra, não sai mais. A gente pode até sair dela e ir para outro setor, mas a educação social não sai mais da gente. (Educadora E)

São os mesmos sentimentos de doação e missão que parecem impedir, por vezes, maior organização política por parte dos educadores. Mesmo assim, mediante parcas condições de trabalho, falta de recursos financeiros e materiais, principalmente, entre os que atuam em organizações governamentais, questões como carga horária excedente e vínculos profissionais precarizados são incorporadas aos poucos nos debates entre os educadores, informa a Educadora F. Talvez essa pequena atenção a um debate sobre as condições de trabalho seja devida ao comprometimento e implicação que demonstram ter com os sujeitos com os quais atuam. Acrescenta-se ainda que é corrente a ideia de que "a história de vida deles [dos atendidos] é tão forte que tu te sente um pouco envergonhada porque tu tem uma casa, tu tem uma família, e eles não têm nada disto", enfatiza a Educadora D. $\mathrm{Ou}$, como acrescenta a Educadora $\mathrm{H}$ : "Olha, eu tenho, eu vivo um paraíso na Terra em relação ao que eles vivem".

Há aparentemente uma fragilidade entre os sujeitos dos socioeducativos que parece justificar a própria ação de doação dos educadores, que se sentem impelidos e sensibilizados diante de uma "fraqueza" social. Essa dimensão da doação parece contribuir para que se retardem os debates e enfrentamentos em relação à precariedade das condições de trabalho e de remuneração. Suspeitamos disso porque, quando nos grupos de pesquisa-formação se propõe o debate sobre a profissionalização ${ }^{4}$ do educador, vemos a proposta se esvaziar em detrimento de outros temas como o planejamento e as estratégias pedagógicas das práticas.

\section{Definindo o socioeducativo}

Quanto ao conceito de socioeducativo, os educadores não utilizam nenhuma definição conceitual, dada a priori. Entretanto, quando exercitam a definição de um conceito para o campo de atuação profissional, fazem-no comparativamente à escola, e o socioeducativo passa a ser caracterizado como um espaço diferente, porém complementar, à instituição escolar.

"Para mim o socioeducativo tem que estar vinculado à escola, acho que tem que ser um projeto ligado à escola", diz o Educador K . O socioeducativo "é essa coisa de resgate de valores, de princípios em sociedade, essa coisa de respeito com a diferença, a diversidade que se fala" (Educadora D). "São projetos de educação não formal, que têm um objetivo específico de cada programa” (Educadora E). Por sua vez, a dimensão do acolhimento também merece destaque e é pautada especialmente pela Educadora H, quando afirma: "Eles gostam de estar ali. Ali eles se sentem bem".

4 Atualmente, a regulamentação da profissão tramita na Câmara Federal, por meio do projeto de lei n. 5.346/09. Disponível em: <http://www.camara.gov.br/proposicoes Web/fichadetramitacao?idProposicao=437196>. Acesso em: 24 maio 2012. 
Também é importante o destaque dado à flexibilidade, por parte dos educadores. "A gente tem um programa, tem um conteúdo para trabalhar, coisas que a gente pretende passar para os alunos, para os educandos, mas a gente não está preso a uma estrutura fechada" (Educador J). Ou como diz a Educadora E, que sugere que a escolha dos jovens tem prioridade: "Que atividades nós vamos fazer? Vamos realizar uma atividade conjunta? Desejam uma atividade recreativa?". Essa suposta flexibilidade parece jogar um importante papel na composição do amálgama de significados que a prática assume para os educadores. Se, por um lado, trata-se de um trabalho marcado pela precarização e pela flexibilização dos direitos sociais; por outro, oferece aos educadores a oportunidade de criação de inúmeras possibilidades de escolhas. É preciso lembrar que, quando os educadores se dedicam a discutir e pensar a criação de modos peculiares de realizar seu trabalho, eles também estão debatendo e pensando a criação de modos singulares de si mesmos.

Tal condição remete a prática do educador ao plano da experiência da atividade, tal como definida por Schwartz (2006), para quem a atividade nunca é inteiramente heterodeterminada, pois a vida - e o trabalho como manifestação da vida - sempre escapa a qualquer tentativa de antecipação rígida. Trata-se de uma condição de autonomia e autoria de insuspeitáveis consequências, pois, segundo o referido autor, mesmo no mais simples ato de execução, os trabalhadores são desafiados a fazer escolhas, constrangidos a decidir caminhos, mesmo que num plano infinitesimal. A liberdade de escolha concede aos educadores a vantagem de incessantemente renormatizarem seu trabalho ante seus próprios referenciais de vida.

São várias as ideias que surgem quando se busca um conceito sobre o que seja um socioeducativo. A complementaridade em relação à escola, a não formalidade, o acolhimento e a flexibilidade têm destaque. Entretanto, quando o exercício era no sentido de demonstrar as diferenças dos projetos comparativamente à escola, vimos, historicamente, o discurso do acolhimento se constituir num referente importante. Porém, atualmente, o acolhimento ${ }^{5}$ ressaltado como uma importante característica socioeducativa é também dimensão central no âmbito das escolas e de suas políticas de inclusão.

5 É interessante pensarmos as diferentes formas pelas quais podemos compreender o que significa acolhimento. Derrida (2003), por exemplo, instiga-nos a pensar a ambiguidade presente nesse conceito, por meio de uma relação intrínseca que existe entre acolhimento e hospitalidade. Para que possamos acolher o outro, necessitamos de determinadas condições: acolhe-se em um lugar, apropria-se de um lugar para acolher o outro ou acolhe-se o outro para apropriar-se de um lugar e falar uma linguagem de hospitalidade. A acolhida só é possível quando se tem um lugar para acolher (a morada); acolher o outro é pôr em questão minha liberdade. É desse modo que Derrida pensa a política da hospitalidade, também atravessada por uma política de poder. No entanto, a ambiguidade encontra-se no fato de que o acolhimento é também permeado por uma incondicionalidade, ou seja, acolhe-se na gratuidade mesma, na abertura absoluta ao outro. Como acolher dentro de uma estrutura fechada? A abertura, a não rigidez de programas levaria a outra ideia de acolhimento? São questões que advêm da pesquisa, num particular diálogo com Derrida, e que serão desenvolvidas oportunamente. 
Talvez a flexibilidade da estrutura seja o grande elemento diferenciador dos socioeducativos em relação à forma pedagógica escolar, porque, conforme anteriormente mencionamos, a flexibilidade abre espaço para a atividade plena, no sentido atribuído por Schwartz (2006). E, mesmo que tenham certas práticas formalizadas de modo crescente, ${ }^{6}$ os socioeducativos estão longe da rigidez dos currículos escolares, e isso se traduz para os educadores num espaço de liberdade da prática educativa, a qual repercute na forte implicação por eles demonstrada.

Observa-se, outrossim, que há por parte dos educadores uma autorização para o exercício da burla ${ }^{7}$ como forma de resistência. Essa modalidade de agir em educação é problematizada por dois educadores em um dos grupos de pesquisa-formação. Afirma o Educador J: "O que o Educador I faz é burlar o seu próprio planejamento. Não se trata de burlar o projeto em si, o projeto pedagógico em seu sentido amplo, mas em se permitir fazer de outro jeito aquilo que foi pensando por ele mesmo quando do planejamento do trabalho". ${ }^{8}$

Outra questão que remete ao conceito de socioeducativo é o caráter compensatório de tais práticas, conforme referido anteriormente. Ao mesmo tempo em que fica creditado que os socioeducativos estão voltados especialmente a crianças e jovens pobres, do ponto de vista socioeconômico, e que esses, muitas vezes, são reconhecidos como sujeitos por vezes indisciplinados, com baixa autoestima; é evidente que, diante desses serviços, nos defrontamos com a realidade de uma sociedade em que ainda é precária a ação de Estado, em especial no apoio a determinados segmentos sociais. O que resulta, por parte dos educadores, na compreensão de que:

o socioeducativo é um espaço apropriado para atender uma necessidade que foi criada porque alguém está sendo incompetente. Isto é uma maneira até grosseira de falar, mas é assim que eu sinto [...] se existe uma demanda que cresce cada vez mais, é porque alguém está falhando. Enfim os socioeducativos é para dar conta dessas questões que não têm sido resolvidas. Esse é o conceito para mim, dentro daquilo que eu vivo. (Educador I)

Tal interpretação expressa certo deslocamento entre o que usualmente se compreende como sendo relativo ao sujeito em situação de vulnerabilidade. De

6 Conforme sugerem Moura e Zucchetti (2010, p. 632), "o atributo formal das práticas de educação fora do contexto escolar, de modo crescente, evidencia-se em processos e procedimentos que contam com a presença de um corpo docente, metodologias definidas, mecanismos de avaliação interna e externa, entre outros, em ações que valorizam (muito) as regras, o ritual; totalmente adequadas para ocasiões solenes, protocolares que, por vezes, até lhes visam conferir um caráter sério e oficial".

7 Destaca-se que o ato de burlar não está dado pelo seu sentido pejorativo e muitas vezes negativo do ato de burlar. Burlar aqui diz do ato de recriar o planejado, considerando-se que há distância entre o planejado e o efetivamente realizado. O que corresponde à noção de atividade em Schwartz (2006), assumida por nós neste artigo.

8 Aqui adentramos a questão central dos estudos previstos nesta pesquisa. Entretanto, não detemos ainda um conjunto de dados que permita tratar o tema de forma mais intensa. Fica neste artigo o registro de que esse tema será trabalhado em publicações posteriores. 
forma geral tal expressão, no seu uso cotidiano, diz de uma situação social em que o "sujeito de risco" ameaça o semelhante, de onde se constrói a ideia de que os jovens são seres potencialmente agressivos, violentos etc. $\mathrm{O}$ educador I contribui problematizando tal assertiva e sugerindo que a vulnerabilidade é construída socialmente e nesse sentido busca compreender quais situações fragilizam, mais ou menos, determinados segmentos da sociedade; o que sugere a presença de uma sociedade vulnerabilizadora.

Há de se pensar, dessa forma, que as situações de vulnerabilidade não se referem às pessoas, e sim às suas experiências de inserção social ou de ausência delas. A baixa escolaridade, os altos índices de repetência, a precariedade de inserção no mundo do trabalho, a quase ausência de vínculos formais de emprego, as ocupações inexpressivas e a baixa remuneração sugerem indicadores de um grupo socialmente desprivilegiado, objeto de preconceito, composto por seres que são fragilizados por uma sociedade altamente excludente e que são fixados nessa condição num movimento entre a integração e a desintegração, o pertencimento e o não pertencimento. São esses, em tese, os jovens que são atendidos nos socioeducativos.

\section{Definindo a natureza da ação socioeducativa}

Outra categoria abordada diz respeito à natureza do trabalho nos socioeducativos. Os educadores ressaltam a dimensão educativa do projeto destacando uma modalidade de educar que se dá pelo agir; referindo a educação como prática (social). Nessa dimensão destacam a presença de projetos político-pedagógicos que norteiam as ações nas instituições.

As aprendizagens que acontecem no interior dos projetos são evidenciadas como experiências que se vivem em conjunto: palestras, visitas orientadas, viagens, atividades culturais, as quais são destacadas como importantes estratégias formativas do coletivo, no qual os educadores também dizem aprender.

Quanto à aprendizagem dos jovens, vale ressaltar a fala da Educadora F. "Da minha experiência com a pesquisa, fui me dando conta de que produzir perguntas poderia virar uma metodologia de trabalho". Encorajá-los a questionar o uso de drogas, conflitos familiares, entre outros, é o caminho utilizado pela referida educadora. Esta posição corrobora os escritos de Freire e Faundez (1985, p. 29), que insistem na necessidade de "estimular permanentemente a curiosidade, o ato de perguntar [...]. Há uma radicalidade na existência, que é a radicalidade do ato de perguntar". $\mathrm{O}$ ato de produzir perguntas também orienta o trabalho da Educadora $\mathrm{B}$.

Com a ajuda do Kiko (um boneco tipo móbile), conhecido dos adolescentes, organizamos entrevistas que foram realizadas com moradores do bairro, artistas, profissionais da assistência social. As perguntas eles produziram a partir da sua curiosidade sobre cada um desses.

Sendo assim, a natureza do socioeducativo, no que tange à dimensão educativa, diz de uma modalidade de educar que favorece o diálogo com o cotidiano. Favorece a intervenção no espaço público, as relações interpessoais, orientando uma educação pela ação. A produção da pergunta não somente favorece a aquisição 
de informações, como também produz conhecimento. Educar-se é experienciar, é produzir a disponibilidade para o diálogo, conforme afirma Freire, em Pedagogia da autonomia (1996). ${ }^{9}$

Por sua vez, a dimensão social dos socioeducativos é unânime entre os educadores que referem os projetos pela sua forte ênfase na ação assistencial. Nesses casos, ao invés da ênfase presente na dimensão educativa, ressaltada no campo das aprendizagens, o assistencial como referência remete ao reconhecimento e à identificação de sujeitos. Quais sujeitos são atendidos nos socioeducativos? Por que estão afetos às políticas de assistência social? Isso quer dizer que o projeto deve dar conta de um tipo de jovem: "o jovem do Bolsa Família [...] e dizer para eles quem são" (Educadora F). E resulta na compreensão de que o qualificativo social dos socioeducativos reforça o caráter compensatório das ações, o que é também reiterado pela sua presença nos bairros de periferia da cidade, demarcando o território e a classe social como elementos que identificam a condição de pobreza socioeconômica das famílias dos jovens atendidos.

À primeira vista, pode parecer que há certa supremacia do assistencial sobre o educativo nas práticas dos educadores. Algo como certo esquecimento da dimensão educativa diante das demandas sociais. Entretanto, tendemos a pensar que essas dimensões estão autoimplicadas, isto é, que o educativo e o assistencial se apresentam como experiências complementares ali onde, por vezes, é possível verificar tanto a reafirmação da identidade de uma natureza, quanto sua produção.

\section{As estratégias pedagógicas na educação pelo agir}

Quanto às estratégias pedagógicas, a atuação dos educadores se dá especialmente pela intervenção na modalidade de oficinas, nas quais o esporte, a informática, a dança, o teatro e a conversação são saberes que movimentam as ações pedagógicas. Essas são baseadas nos princípios do "aprender fazendo" que, ao privilegiar a presença do coletivo de crianças e jovens, foca a prática pedagógica mais no grupo que na pessoa. Seguindo a modalidade da intervenção em grupo, as assembleias também são apresentadas como importantes estratégias e são utilizadas pelos educadores para colocar o jovem no centro do processo educativo e/ou para buscar sua adesão para determinada ação.

É relevante destacar a presença do que podemos nomear de temas geradores, estratégias utilizadas pelos educadores. Os temas geradores dão ênfase para as reflexões atinentes à vida dos sujeitos: conflitos geracionais, condição social e escolaridade estão entre os temas centrais e servem, segundo a Educadora E, "para educar pelo agir”. De forma geral, os educadores também ressaltam a aceitação e a diversidade como elementos que orientam as estratégias pedagógicas. A inclusão de todos é perseguida e se dá substancialmente pelo reconhecimento de que o outro

9 Segundo a Educadora B, o estudo da obra Pedagogia da autonomia pelo coletivo dos educadores que atuam no Projovem Adolescente foi decisivo para adaptar a metodologia de trabalho com os jovens à perspectiva freiriana, no que tange ao uso da palavra para produzir perguntas e gerar diálogos. 
(criança e jovem) é capaz de conviver em sociedade. Trata-se de uma metodologia que, embora não claramente, remete-nos ao melhor da tradição da educação popular.

É possível afirmar que são os ingredientes relativos à diversidade e ao reconhecimento da realidade de exclusão social que atingem os sujeitos afetos aos socioeducativos que sustentam as questões para as quais se voltam o planejamento das atividades. Observa-se que esse planejamento geralmente é realizado de forma coletiva; embora referencie situações mais específicas e individuais, ele se constrói coletivamente, em encontros, nos quais se planejam as atividades que serão realizadas, preferentemente, na modalidade de oficinas, conforme o aqui exposto anteriormente.

Entretanto, percebem-se algumas diferenças, relativamente à forma de planejar, entre as organizações governamentais, não governamentais e do terceiro setor. Nas ações desempenhadas pelo poder público, seguem-se mais as orientações discutidas coletivamente, em que a presença do orientador/gestor na figura do pedagogo garante as deliberações da política pública, no caso os percursos metodológicos do Projovem Adolescente. Diz a Educadora F:

uma coisa que eu tenho como alguém responsável por coordenar um grupo, por organizar as reuniões, é de que nada eu discuto individualmente, tudo é no grupo. Se a gente vai se constituir num grupo, a gente tem que ter a coragem de dizer tudo aí.

A realidade de pensar e planejar sem diretrizes mais amplas está presente de forma mais intensa entre os educadores que atuam nas organizações não governamentais e do terceiro setor. Nesses casos, a presença de um plano de intervenção local é prática institucional orientada pelos objetivos do projeto. Quer entre o coletivo dos educadores ou na prática direta com os jovens, é interessante pontuar que o planejamento aparece essencialmente como um espaço de construção e desconstrução, numa prática de constante negociação. Conforme a Educadora $\mathrm{C}$,

o planejamento, ele sempre acontece previamente, porque ele é fundamental e, isto eu levei um tempo para descobrir. E como ele faz a diferença, assim na vida do educador; a gente vai planejando durante o mês, o semestre, e assim por diante. Sempre a gente procura fazer uma conversa com os adolescentes [...] assim eu parto daquilo que eles me trazem de assunto, temática, e vou encaixando na rotina semanal.

Outro fator que merece destaque é que o planejamento representa também a possibilidade da sua modificação. Procedimento este que se assenta numa espécie de autonegociação: planejar, pensar a ação que se apresenta e propor a sua ausência ou o não cumprimento.

Por que eu não cumpro? Porque se eu seguir à risca e cumprir o que eu planejei, eu perco muito. Eu perco por quê? Porque quem define o andamento são eles, eu permito que isso aconteça. A gente percebe, dos relatos, das conversas que eles têm entre eles, a gente talvez ouça, das conversas que eu tenho com os colegas (educadores), daquilo que eles mostraram numa aula anterior, daquele 
comportamento que a turma tá tendo naquele dia. Isso define a próxima aula, a próxima semana, talvez até o próximo mês, depende muito da intensidade do que acontece. Quando, um exemplo que até não é tão expressivo, mas se por acaso um dia eles estão dispersos, e eu tinha uma atividade programada, eu mudo. [...] É tanta coisa que acontece, que de tudo que tá acontecendo, eu tenho que tirar aquilo que eu entendo naquele momento como mais importante, pra ser trabalhado na semana seguinte. (Educador I)

Segundo Pörtner (2002), em estudo sobre o planejamento, a modalidade de plano controla a ação, diferenciando-se daquelas que permitem improvisar o agir. Para produzir essa afirmativa, o autor parte de três perspectivas de planejamento disciplinar: o racional-normativo, o estratégico-situacional e o participativo. Este último, ao propor um planejamento de tipo relacional, destaca-se por valorar o vínculo.

Um plano que valora, pensa e improvisa a ação, que funciona considerando o vínculo que se estabelece entre educadores e educandos, é o que se evidencia na fala acima. Marcada pela estética da relação, essa modalidade de planejamento se apresenta como uma artesania, partilha de palavras, ideias, gestos, que dizem do cuidado com o outro, afirma Pörtner (idem).

Das experiências que se produzem no campo das estratégias pedagógicas e seu planejamento, vale destacar que estamos diante de práticas que sugerem a autonomia dos próprios educadores. Segundo a Educadora F, "a gente precisa ser reconhecida e aprender a ser autônoma pra desenvolver isso no outro. Porque não dá pra falar sobre autonomia, o grupo tem que fazer a experiência da autonomia pra poder desenvolver isso com os jovens". O exercício da autonomia presente nas formações em serviço, nos planejamentos individuais e coletivos, diz de um agir autônomo.

\section{A ARTESANIA DO FAZER E DAS PALAVRAS: QUESTÕES QUE ECOAM PARA QUE OS SENTIDOS POSSAM ACOLHER NOVOS SENTIDOS}

Os argumentos apresentados neste artigo resultam da aproximação com o campo empírico da pesquisa em execução e, conforme afirmamos anteriormente, desafiam-nos a pensar sobre as inúmeras facetas e condições em que ocorre o fazer desses educadores. Nesse sentido, de forma geral, buscamos pensar o trabalho no socioeducativo como um lugar de artesania, tanto pela ausência de um conceito previamente dado, quanto por não estar preso a uma prescrição pedagógica clássica. Enfatizamos o fato de o planejamento realizado pelos educadores constituir-se num processo de negociação, no qual as demandas, após ouvidas e debatidas, transformam-se em propostas de ação. A utilização da intuição e da sensibilidade como estratégias de ação, ao emergirem da vida de cada um dos educadores, também dimensiona a artesania na prática pedagógica dos que atuam em socioeducativos. Entretanto, verificamos que é impossível separar a ação pedagógica da dimensão compensatória de tais projetos. 
Também é importante ressaltar o que parece próprio dessas práticas: uma margem maior de liberdade, tanto para os educadores na ação educativa como para os próprios jovens que frequentam os projetos. Muito embora com características que em muito vêm se assemelhando à educação escolar, os socioeducativos, por meio de seus tempos, formas e condições para a socialização, não chegam a se desenvolver como uma prática que se baseia na prescrição, o que nos permite pensar numa margem de liberdade no fazer dos educadores (Zucchetti; Moura, 2010). É no âmbito do planejamento (em sua relação com a flexibilidade) que são percebidas as maiores diferenças entre os socioeducativos e a educação escolar.

Do contexto que emerge das entrevistas e no qual a pesquisa se propõe investigar, a questão da formação de educadores é central. A formação em serviço enquanto uma modalidade que ocorre "justaposta à experiência do ofício e no próprio local de trabalho" (Moura, 2009, p. 159) tem destaque. Entretanto, é na dimensão do coletivo, presente nesta modalidade de formação, que se vê melhor definida a natureza do trabalho, o esforço na construção de um planejamento e a busca do reconhecimento da função de educador. A autoformação também se faz presente entre os educadores, não aquela que individualiza o processo, mas que potencializa as singularidades por meio das experiências da partilha do jeito de cada um fazer algo.

Nesse sentido, merece ser mencionado que, embora os educadores investigados refiram adotar estratégias de ensino próprias da educação popular, eles não parecem se reconhecer como educadores "populares". No entanto, no que tange ao modo de pensar sua prática, ao assumirem alguns pressupostos da educação popular, abrem uma perspectiva teórica que impõe problematizar o contexto (não só local, mas global, das problemáticas vividas nesses espaços) e, ao mesmo tempo, inserem-se nesse contexto, problematizando a precarização do trabalho por meio de uma prática crítico-reflexiva.

E possivel ao educador discutir e pensar acerca de um contexto que produz uma realidade de trabalho e o seu próprio trabalho, sem pensar a sua realidade de trabalho? É desse modo, que se torna importante indagar até que ponto os educadores compreendem estar imersos em um contexto que possui, pelo menos, três funções vitais à manutenção de um modelo de sociedade desigual.

Estamos nos referindo às funcionalidades do terceiro setor, as quais, a um só tempo, garantem a flexibilização dos direitos do trabalho por meio da flexibilidade do trabalho no socioeducativo; fazem prevenção à "marginalidade" por meio de atividades de ocupação do tempo livre dos jovens e crianças em situação de vulnerabilidade; e sugerem a preocupação com o acolhimento do outro, o que possibilita, entre outras coisas, a formação para uma visão de cidadania.

Outro elemento que destacamos refere-se às narrativas como experiências formativas que, ao reforçar a modalidade de autoformação, permitem aos educadores buscarem outra relação que não se constitui pelo eixo da verticalidade. Isso significa que as experiências partilhadas nos permitem pensar em um processo autoformativo em que a presença do outro é fundamental.

E, por fim, apresentamos a dimensão de complementaridade que os projetos socioeducativos assumem em relação à escola. A complementaridade está presente 
nos estudos que definem conceitualmente essa prática de educação. Mas também está encarnada na forma como os educadores compreendem o sentido desses projetos. Pensar o caráter complementar nos reporta a pelo menos duas percepções sobre essa questão. O complementar surge porque a escola não dá conta da integralidade da ação educativa e, desse modo, é preciso construir outros espaços que assumam essa função.

No entanto, podemos pensar também que o trabalho realizado nos espaços socioeducativos não diz mesmo respeito ao trabalho e à função da escola. Ou seja, estamos diante de uma realidade que produz outra ideia de escola. Diante dessa nova realidade, a educação escolar se vê desafiada a incorporar determinados elementos que pareciam fazer parte do processo educativo (como, por exemplo, a construção da cidadania, e não somente a transmissão de conhecimento). É assim que podemos compreender programas como o "Mais Educação", que trazem práticas da educação não escolar para dentro da escola e, com isso, geram tensões e outras implicações no campo da educação.

\section{REFERÊNCIAS}

Antunes, Ricardo. O caráter polissêmico e multifacetado do mundo do trabalho. Revista Educação, Saúde e Trabalho, Rio de Janeiro: Fundação Oswaldo Cruz, v. 1, n. 2, p. 53-61, 2003.

Associação de Educadoras e Educadores Sociais do Estado de São Paulo. Educador Social - Cadastro Brasileiro de Ocupações. São Paulo, 2010. Disponível em: <http://aeesspblog.blogspot.com.br/2010/04/5153-05-educador-social-cadastro.html>. Acesso em: 20 set. 2013.

Brasil. Comunicados da presidência. Pobreza, desigualdade e políticas públicas. IpeA, n. 38, 12 jan. 2010. Disponível em: <http://www.asabrasil.org.br/UserFiles/File/ Pobreza_desigualdes_pp_ipea.pdf $>$. Acesso em: 20 set. 2013.

Calegare, Marcelo Gustavo Aguilar; Júnıor, Nelson Silva. A "construção" do terceiro setor no Brasil: da questão social à organizacional. Revista Psicologia Política, Belo Horizonte: ABPP, v. 9, n. 17, p. 129-148, jan./jun. 2009.

Carvalho, Maria do Carmo Brant de; Azevedo, Maria Júlia. Ações complementares à escola no âmbito das políticas públicas. 2004. Mimeografado.

Derrida, Jacques. Anne Dufourmantelle convida Jacques Derrida a falar da hospitalidade. São Paulo: Escuta, 2003.

Freire, Paulo. Pedagogia do oprimido. 9. ed. Rio de Janeiro: Paz e Terra, 1981.

. Pedagogia da autonomia: saberes necessários à prática educativa. 6. ed. Rio de Janeiro: Paz e Terra, 1996.

1985.

. Faundez, Antonio. Por uma pedagogia da pergunta. Rio de Janeiro: Paz e Terra,

Haddad, Sérgio. "Homenagem". Revista Brasileira de Educação, Rio de Janeiro: ANPEd; Campinas: Autores Associados, v. 14, n. 41, p. 370, maio/ago. 2009. 
Lima, Jozilda Berenice Fogaça. Práticas educativas no âmbito da educação não escolar: reflexões sobre o fazer e o saber de educadores sociais. 2010. Dissertação (Mestrado em Inclusão Social e Acessibilidade) - Centro Universitário Feevale, Novo Hamburgo, 2010. Moura, Eliana Perez Gonçalvez de. Gestão do trabalho docente: o "dramático" uso de si. Educar em Revista, Curitiba: UFP, n. 33, p. 157-169, 2009.

.Zucchetti, Dinora Tereza. Educação além da escola: acolhida a outros saberes. Cadernos de Pesquisa, São Paulo: Fundação Carlos Chagas, v. 40, n. 140, p. 629-648, ago. 2010.

Pörtner, Cristiano Georgen. Planejamento à força, pensa-ação que se apresenta; à fraqueza, pensa ação pela ausência: metateoria de planejamento: e improviso. 2002. 185f. Tese (Doutorado em Educação) - Universidade Federal do Rio Grande do Sul, Porto Alegre, 2002.

Schwartz, Yves. Entrevista: Yves Schwartz. Revista Trabalho, Educação e Saúde, Rio de Janeiro: Fundação Oswaldo Cruz, v. 4, n. 2, p. 457-466, 2006.

Zucchetti, Dinora Tereza; Moura, Eliana Perez Gonçalves de.Práticas socioeducativas e formação de educadores: novos desafios no campo social. Ensaio, Rio de Janeiro: Fundação CESGRANRIO, v. 18, n. 66, p. 9-28, jan./mar. 2010.

\section{SOBRE AS AUTORAS}

Dinora Tereza Zucchetti é doutora em educação pela Universidade Federal do Rio Grande do Sul (UFRGS). Professora titular da Universidade Feevale (FEEVALE).

E-mail: dinora@feevale.br

Eliana Perez Gonçalves de Moura é doutora em educação pela Pontifícia Universidade Católica do Rio Grande do Sul (PUC-RS). Professora titular da Universidade Feevale (FEEVALE).

E-mail: elianapgm@feevale.br

Magali Mendes de Menezes é doutora em filosofia pela Pontifícia Universidade Católica do Rio Grande do Sul (PUC-RS). Professora da Universidade Federal do Rio Grande do Sul (UFRGS).

E-mail:magalimm@terra.com.br

Recebido em outubro de 2012

Aprovado em novembro de 2013 
